\title{
Education, age and skills: An analysis using PIAAC data
}

\begin{abstract}
The main aim of this article is to analyse the change of adult skills, as captured by cognitive skills assessed in PIAAC, across age cohorts, taking into account that the quality of schooling may change from one cohort to another. We estimate a model that relates numeracy and literacy skills to age, schooling, gender and variables related to both family background and labour market performance. The specification allows us to control for changes in the efficiency of the transformation of schooling into skills when drawing age-skill profiles. Our results show that the effect of ageing on skills, once isolated from cohort effects related to schooling, decreases monotonically across consecutive cohorts. The change of the efficiency of the transformation of schooling into both numeracy and literacy skills shows a remarkably similar pattern. Nonetheless, this change differs substantially between education levels, with the efficiency of the transformation of schooling into skills showing a steadier profile for intermediate than for higher education. Finally, empirical evidence is provided for the decomposition of the differences in the skill levels of the older vs. the prime age generations. The results suggest that the progressive expansion of schooling across younger generations partially offsets the negative effect of the irrepressible ageing of society on skills.
\end{abstract}

\section{KEYWORDS:}

adult skills, ageing, age-skill profiles, schooling 


\section{Education, age and skills: An analysis using PIAAC data}

Jorge Calero, Inés P. Murillo Huertas \& Josep Lluís Raymond Bara

\section{Correspondence}

Jorge Calero, Universidad de Barcelona \& IEB, Facultad de Economia y Empresa, Universidad de Barcelona, Avenida Diagonal, 69008034 Barcelona, Spain

Email: jorge.calero@ub.edu

Inés P. Murillo Huertas, Universidad de Extremadura, Facultad de Ciencias Económicas y Empresariales, Avda. de Elvas, s/n, 06071 Badajoz, Spain

Email: ihuertas@unex.es

Josep Lluís Raymond Bara

Universidad Autónoma de Barcelona \& IEB, Plaça Civica, 08193 Bellaterra, Barcelona, Spain

Email: josep.raymond@uab.cat

\section{INTRODUCTION}

Studies dealing with human capital accumulation have traditionally relied upon such indicators as years of schooling or educational levels to proxy knowledge. However, as noted by Wößmann (2013), although commonly used in empirical research, these proxies misspecify the link between education and the stock of human capital since they ignore the quality of schooling, leading by implication to inaccurate estimations. Focusing specifically on adult capabilities, conventional measures could fail in their attempt to gauge individuals' real knowledge for several reasons (Borghans, Green, \& Meyhew, 2001). Knowledge may vary depending on the effectiveness of the transformation of schooling into skills. Moreover, the change of these skills beyond schooling, especially because of their use (or lack of use) in the labour market, could also determine how accurately attained education reflects individuals' actual skills. In this regard, direct measures of adult skills provide a further advance in the attempt to give a reliable measure of individuals' skills as key drivers of economic development, with empirical evidence concluding that not only schooling, but also acquired skills have a robust and strong effect on individual earnings, income distribution and economic growth (Hanushek \& Woessmann, 2008).

If we accept this distinction between schooling and skills, then we need to determine how the latter are produced. Educational production functions have typically underpinned analyses of which factors influence students' achievements during their childhood and teens (Hanushek, 1979; 1997). In this context, there is a general 
consensus in concluding that not only years of education, but also other relevant features such as personal characteristics (e.g., gender) and family socioeconomic background drive the acquisition of skills even beyond schooling (Björklund \& Salvanes, 2011; Mazzona, 2014). Moreover, since human capital is a dynamic concept, as individuals leave school and age, other sources of knowledge emerge.

The change of skills both over the life cycle and over time has attracted special attention in the literature. Skills may increase as people enter the labour market and accumulate experience, but they may also depreciate as a consequence of a lack of use. As De Grip and Van Loo (2002) stress, interruptions to employment or jobs below employees' attained level of education derive in a non-use or an insufficient use of abilities that cause skill obsolescence by atrophy. In this regard, although skill gains and losses with ageing vary from one person to another, age-skill profiles tend to show a negative trend, with skills declining from adulthood onwards (Hertzog, Kramer, Wilson, .\& Lindenberger, 2009).

Nonetheless, as noted by Desjardins and Warnke (2012), observed differences in skills over time should not be attributed solely to ageing. This means that age differences (between-person comparisons) differ from age changes (within-person comparisons). Cohort changes due to social factors and/or neurophysiological changes of successive birth cohorts could pollute purely ageing effects. By implication, differences in skills over time could reflect more than one source of change. In practice, the scope of the analysis is conditioned by data design, with cross-sectional observations being suitable for examining differences in skills between individuals belonging to different age cohorts at the same period and, by contrast, longitudinal datasets being appropriate to determine the trajectory of individuals' skills over their lifespan.

Assuming that skills can be proxied by skills in adulthood, empirical evidence based on cross-sectional data from the International Adult Literacy Survey (IALS) and the Adult Literacy and Lifeskills Survey (ALL) provides age-skill profiles that decline from the age of 30 onwards (Willms \& Murray, 2007; Green \& Riddell, 2007). Moreover, on the basis of data from the Longitudinal Study of Adult Learning (LSAL), Reder (2009) reported a negative trend in literacy-age curves, with literacy peaking in the mid-30s and proficiency being lost from then onwards. Taken as a whole, these findings suggest that literacy skills decline not only over time, but also over the lifespan, with both cross-sectional and longitudinal data providing a consistent negative empirical relationship between ageing and skills. More recently, combining information from the IALS, ALL and the first wave of the Programme for the International Assessment of Adult Skills (PIAAC), Desjardins and Warnke (2012) found that unconditional age-skill profiles increased up to the early 30s and then decreased until retirement; nonetheless, when account is taken of education, the results provide monotonically decreasing age-skill profiles from the age of 16.

However, as discussed above, these results do not explicitly take into account the fact that social factors - in particular, the quality of schooling - could change from 
one cohort to the other. If this is the case, age-skill profiles could track not only the effects of ageing, but also changes in the efficiency of the transformation of schooling into skills through successive cohorts. The aim of this article is to provide some insight into this question. The specification allows us to disentangle cohort differences in skills resulting from ageing from those due to variations in the quality of schooling. 'The quality of schooling' is therefore a key concept in this article and deserves to be clarified. Our specification includes information about the years of education attained, but the effect of each year depends on two factors: on the one hand, the purely quantitative one, which is well described by the variable we use; and on the other, a qualitative factor related to how different education systems transform (with greater or lesser effectiveness) years of education into skills. This qualitative factor is labelled here as 'school quality' and is composed of a series of unobservable elements which vary by countries and periods. Among these elements we could underline, for example, the quality of the teaching staff, the type of pedagogical practices, the school leadership and the stability of the staff. These elements in our specification are not separately identifiable, but are all related to the concept of 'school quality'. Thus, if we compare individuals who belong to a set of countries and have the same years of attained education, gender, age, labour market experience, family background, occupation, etc., we can assume that the differences in the competences identified in PIAAC could be attributed to differences in the quality of the education they received. By so doing, we are able to disentangle cohort differences in skills due to variations in the quality of schooling from cohort differences in skills as a result of ageing [1]. Furthermore, by using educational level instead of years of attained schooling, our proposal allows for cohort changes in the quality of schooling to vary between upper secondary and higher education. Hence, evidence is provided as to (i) whether the efficiency of the transformation of schooling into competences has improved or not over time and (ii) whether there are remarkable differences in the change of the quality of schooling between upper secondary and higher education.

Previous studies have attempted to separate cohort effects from age effects by comparing single age cohorts on repeated, representative cross-sectional data from IALS, ALL and PIAAC (Willms \& Murray, 2007; Green \& Riddell, 2007; 2013; Desjardins \& Warnke, 2012; Flisi, Meroni, \& Vera-Toscano, 2015). This strategy provides information as to whether a cohort as a whole and on average has gained or lost skills with ageing and over time [2]. However, although these studies identify schooling as one of the main drivers of literacy skills, none focus on the role played by changes in the quality of schooling in driving the results. Although it is beyond the scope of our research to identify which factors determine the observed changes in the efficiency of transformation of schooling into skills, to the best of our knowledge our article is among the first to explicitly consider these changes when defining age-skill profiles. 


\section{A DESCRIPTIVE ANALYSIS OF THE DATA}

This study uses the first round of PIAAC data, corresponding to 2012. Conducted by the OECD, this international survey provides high-quality information on the cognitive skills of adults aged 16-65. Although linked to the two previous international surveys measuring adult skills (IALS and ALL), PIAAC includes a greater number of participating countries and assesses domains of cognitive skills beyond that of literacy. Thus, it provides valuable data on adult proficiency and workplace requirements in numeracy, literacy and problem solving in technology-rich environments, all of which are key skill requirements for individuals to participate successfully in society and for economies to develop. In addition, the survey also provides a comprehensive set of variables concerning individuals' demographic characteristics, family background, educational attainment and labour market performance in order to support the main analytical goals of the survey, namely: (i) to determine the level and distribution of adult skills and (ii) to better understand the factors driving these skills over the lifecycle (OECD, 2012).

Some of the 24 countries that participated in the first round of PIAAC were not included in our analysis either because the comparability of their data could not be guaranteed or because of a lack of homogeneous information on some key variables in our model [3]. The analysis focused solely on numeracy and literacy skills, as problem solving in rich-technology environments domain has yet to be implemented by all the participating countries. The numeracy domain assesses 'the ability to use, apply, interpret, and communicate mathematical information and ideas', whilst the literacy domain measures 'the ability to understand and use information from written texts in a variety of contexts to achieve goals and develop knowledge and potential'. In the original survey, both variables were scored from 0 to 500 , although the scores were doubled in our analysis to facilitate the interpretation of the results. Together with these variables, information on (i) educational level, (ii) age, (iii) gender, (iv) immigrant status, (vi) native speaker condition, (vii) family educational background, (viii) labour market experience, (ix) occupation and (x) participation in non-formal learning was used in the estimations.

Table 1 shows the descriptive statistics for the selected sample (which does not include individuals with no information regarding any of the variables considered in the analysis, resulting in around 79,000 observations). The average value of the numeracy (literacy) competency stands at about 542 (549) points, with a sizable standard deviation of around 96 (88) points. The average number of years of attained schooling reaches 12.73 in a population with an average age of 40 and an average labour market experience of 18.21 years. The proportion of first-generation immigrants in the sample is $7.9 \%$, falling to $1.7 \%$ in the case of second-generation immigrants. As regards family socioeconomic background, $38 \%$ of those interviewed $-92 \%$ of whom responded to the questionnaire in their mother tongue - reported having at least one parent who had attained upper secondary education. The figure corresponding to individuals with at least one parent with higher education is $22 \%$. Two thirds of the sample had a skilled 
occupation. Finally, almost $40 \%$ of the sample participated in non-formal learning in the 12 months preceding the survey.

[Table 1 about here]

Table 2 shows the sample distribution by education level and cohort. The intermediate level (upper secondary and post-secondary non-tertiary education) is the most frequently attained (43.38\%), followed by higher education $(29.79 \%)$ and, finally, basic education (26.83\%). Adult participants are quite homogeneously distributed by cohort, each representing around 9 to $11 \%$ of the whole sample.

[Table 2 about here]

\section{FORMULATION OF THE MODEL}

The aim of our model is to disentangle the impact of the efficiency in the transformation of levels of schooling into skills (a cohort effect) and the effect of ageing on levels of numeracy and literacy. It should be noted that, although our model specifically enables us to isolate the effect of the quality of schooling on the acquisition of skills, the effect of ageing cannot be captured by our single cross-sectional database (see discussion in section 1). Thus, although we refer to the effect of ageing that our data are able to capture as a 'direct effect of ageing', it should be borne in mind that cohort effects other than changes in the quality of schooling may also be captured by this term [4].

The model is an educational production function as follows:

$$
\begin{aligned}
& \text { Skills }_{i}\left(\text { Pb1000m }_{i} \text { or } \mathrm{Pb1000l}_{i}\right)=\mu+\underbrace{\sum_{h=1}^{10} \beta_{h} \cdot \operatorname{Int}_{i h}+\sum_{k=1}^{10} \alpha_{k} \cdot \operatorname{Sup}_{i k}}_{\text {Educational level dummies by age cohort }}+\underbrace{\sum_{j=2}^{65} \gamma_{j} \cdot D_{i j}}_{\text {Age dummies }}+\delta \cdot \text { Gender }_{i}+ \\
& +\phi_{1} \cdot \text { Inmig }_{i}+\phi_{2} \cdot \text { Inmig } 2_{i}+\theta \cdot \text { Nativespea }_{i}+\tau_{1} \cdot \text { Pared }_{i}+\tau_{2} \cdot \text { Pared } 2_{i}+\tau_{3} \cdot \text { Pared }_{i}+ \\
& +\lambda_{1} \cdot \operatorname{Exp}_{i}+\lambda_{2} \cdot \operatorname{Exp}_{i}^{2}++\pi \cdot \text { Skilled }_{i}+\sigma \cdot \text { Nonformaled }_{i}+\underbrace{\sum_{z=2}^{16} \xi_{z} \cdot \text { Countrydummy }_{i z}}_{\text {Country fix effects }}+\varepsilon_{i}
\end{aligned}
$$

where the dependent variable is an index between 0 and 1,000 referring alternatively to literacy $\left(P b 1000 l_{i}\right)$ or numeracy skills $\left(P b 1000 m_{i}\right)$. The selection of explanatory variables is related to the skill acquisition process in which five factors interact. We used the following variables for each of the factors (our two variables of interest are marked with an asterisk and their construction is explained below) [5].

1) Education level. A functional form of schooling (*).

2) Personal: a functional form of age $(*)$, gender.

3) Family background: Immigrant status (national, first or secondgeneration immigrant), native speaker, parents' educational levels.

4) Participation in the labour market: experience, skilled occupation.

5) Participation in non-formal learning programmes. 
The large number of observations in our sample (around 79,000) enabled us to use a non-constrained functional form for the effect of age on skills. Instead of using a quadratic form or creating dummy variables for decennial or quinquennial age groups, 49 dummies (from 17 to 65 years) were created, using the age of 16 as the reference category. Using this approach, we avoided imposing a specific functional form for the effects of age on skills, which constitutes in itself an added value with regard to previous studies in the same line that use age as a continuous variable or a variable in intervals (Green \& Riddell, 2013).

The functional form of schooling that we used aimed to identify different effects of schooling on skills depending on the year of birth. Coefficients of schooling, which can be interpreted as the efficiency in the transformation of levels of schooling into skills, are thus specific for each age group. Hence, we were able to analyse the change of that efficiency over time. We used ten five-year age groups: the first including individuals born between 1991 and 1995 (aged between 16 and 20 when assessed by PIAAC) and the last including individuals born between 1946 and 1950 (aged between 61 and 65 years when assessed).

We established three categories for schooling level [6]: 'basic' (up to lower secondary education) 'intermediate' (upper secondary, both academic and vocational, and post-secondary non-tertiary education) and 'higher education' (both academic and vocational). The model thus includes two sets of schooling level variables that interact with the age groups, since 'basic' education is the category of reference. In the case of 'intermediate' education, we included ten dummy variables, one for each age group: ' Int $_{\mathrm{i} 1}$ ' took a value of 1 if the individual had an upper secondary certificate and was

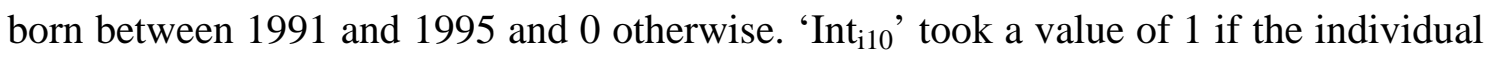
had an upper secondary certificate and was born between 1946 and 1950 and 0 otherwise. For 'higher education', likewise, we included nine dummy variables ranging from 'Sup ${ }_{\mathrm{i} 2}$ ' to 'Sup $\mathrm{i}_{\mathrm{i} 10}$ ', since in this case 'Sup $\mathrm{i}_{1}$ ' corresponds to the null combination of people aged between 16 and 20 having obtained a higher education degree.

As discussed above, the coefficients of the dummy variables that describe the interaction between schooling level and age group can be interpreted as the level of efficiency in the transformation of schooling into skills. This interpretation is possible because the model also includes age dummies which capture the direct effect of age on skills that can be attributed to both biological and behavioural maturation (Desjardins \& Warnke, 2012). Keeping age constant, dummy variables such as 'Int' ${ }_{\mathrm{i}}$ through 'Int ${ }_{\mathrm{i} 10}$ ' capture the time change of the efficiency in the transformation of upper secondary education into skills. For example, a positive trend in the coefficients accompanying these dummy variables points to an increase in the efficiency of the transformation of upper secondary education into skills.

As part of the family background variables, the model included three dummies related to the parents' educational level, adhering to the same three categories used in the case of the individual. Immigrant status was described using two variables: 'immigrant1' for first generation immigrants (with a value of 1 if the individual was born abroad, 0 otherwise) and 'immigrant2' for second generation immigrants (with a value of 1 if both parents were born abroad, 0 otherwise). 
The model also included labour market experience in a quadratic form, by analogy with the human capital model used to explain wages. An alternative approach, using 55 dummy variables to capture the individual's years of work experience, was tested. Both approaches offered almost identical coefficients for our variables of interest. However, we opted for the quadratic form as a more parsimonious approach and because of the better results of the Bayesian Information Criteria (or Schwartz Statistic).

The remaining explanatory variables did not require any additional explanation. They were included to cover the most relevant factors that influenced the process of skills acquisition. Additionally, the model included 15 country dummies (with Belgium as the category of reference).

\section{THE TRANSFORMATION OF EDUCATION INTO SKILLS. RESULTS OF THE ESTIMATION OF THE MODEL}

The results of the estimation of equation 1 for both numeracy and literacy skills are shown in Table 4 (a complete version is provided in Table A.2). Before commenting on these results, it is worth mentioning that the outcomes derived from the use of PIAAC data should be interpreted with caution, given the nature of scoring and levelling skills in that survey, discussed in detail by St. Clair (2012). In this sense, the results here should be understood as referring to the population as a whole.

Focusing on the results, the effect of gender was significant for both skills. Keeping the remaining variables constant, men scored 21 points higher than women in the case of numeracy and 4 points higher in the case of literacy. Being a first- or secondgeneration immigrant also entailed a penalty for both skills. However, the negative effect of being a first-generation immigrant almost tripled that of being a secondgeneration immigrant. Native speakers had a clear advantage in the acquisition of both numeracy and literacy skills, an advantage that roughly translates into an additional 30 points. The effects of cultural capital, proxied by the parents' education level, were also clear: having parents that attained upper secondary education was associated with increases of 16 and 15.4 points (for numeracy and literacy skills, respectively) in relation to having parents with lower secondary education, which was the reference category. Having parents that attained higher education was associated with increases of 35.9 and 33.9 points in the same domains, respectively.

Years of experience in the labour market and its square presented the expected positive and negative signs, respectively. Being employed in a job that demands qualifications had a positive effect on numeracy and literacy skills. Likewise, having completed a non-formal training programme added around 12 points to both numeracy and literary skills. However, it should be noted that the effect of life-long learning on skills could not be properly addressed using PIAAC data, since the only variable in the dataset which couldbe used referred to training during the last 12 months.

[Table 4 about here] 
The effect of age and the quality of schooling quality will be shown graphically. But, beforehand, in order to fully understand the implications of our results, we show the change of the effects of age on skills without conditioning this change to any other explanatory variable. This unconditioned effect is shown in Figure 1 with a confidence interval of $95 \%$. In line with the empirical evidence reported in previous studies (Desjardins and Warnke, 2012), both numeracy and literacy skills tended to increase up to the age of about 25-30 years. After this, both skills tended to decrease continuously.

\section{Figure 1 about here]}

Figures 2 and 3 show the effects of the two variables of interest in our complete model for different age groups. These effects decompose the aggregate effect of age shown in Figure 1. Specifically, Figure 2 plots the effects of the variable 'age' on skills, which captures the direct effect of ageing in the model. As discussed above, this direct effect may be caused by processes related simultaneously to biological and behavioural maturation and in our model it is isolated from the cohort effect, i.e., possible changes in the way in which the education system is able to transform schooling levels into skills. It seems that the kind of skills measured by PIAAC is negatively affected by this direct effect. The trend appearing in the Figure decreases monotonically for both skills, showing, in both cases, a steep drop at around the age of 20. This could be related to the existence of skills that the individual is able to keep only for a short period of time after leaving formal education. When comparing this trend with that shown in Figure 1, it should be stressed that the change is directly linked to the introduction into the model of those variables in which age interacts with the education level, the contribution of the remaining explanatory variables being less relevant.

Figure 2 about here

Figure 3 plots the effects of the dummy variables in which the level of schooling interacts with the age group (cohort effects due to changes in the quality of schooling), for different age groups. The change over time of these effects provides us with information about changes in the efficiency in the transformation of levels of schooling into skills. For each skill, the upper panel of the Figure refers to the intermediate level of education (upper secondary education), whilst the lower panel refers to higher education. In all four cases, the corresponding $95 \%$ confidence interval is shown between dashes.

\section{Figure 3 about here]}

Figure 3 shows that the effects on numeracy and literacy skills in the case of intermediate education are very similar, as they are in the case of higher education. However, these trends differ markedly if we compare the two education levels. In the case of intermediate education, a significant deterioration occurs for the age group born between 1991 and 1995. For this age group, the attainment of intermediate education (relative to basic education) adds 33 points to their numeracy skills; in contrast, for the age group born between 1946 and 1950 (i.e., the last cohort) the equivalent increase was of 42 points [7]. However, for the rest of the age groups, the efficiency of the 
transformation of the intermediate level of education into skills remains steady, with only a significant increase in the age group born between 1970 and 1975.

In the case of higher education, the pattern is quite different, showing a monotonic increase in the efficiency of transformation of schooling into skills for all the age groups born between 1945 and 1975 and, thereafter, a steady change with only a slight but significant decrease for the two youngest age groups, corresponding to those born between 1980 and 1990 [8].

The results of our model can be summarised in four patterns: (i) the direct effect of ageing, isolated from cohort effects related to schooling, decreases monotonically for all the age groups considered; (ii) the cohort effects we identified, relating to the efficiency of transformation of schooling into skills, are very similar in the case of numeracy and literacy skills; (iii) the cohort effects identified by the model are substantially different by educational level; and (iv) whilst the transformation of upper secondary education into skills shows a steady level of efficiency over time (the only exceptions being the youngest age group and a 'peak' presented by the age group corresponding to those born in 1970-75), in the case of higher education the efficiency when transforming schooling into skills increases for all the age groups from 1945 to 1970, decreasing slightly thereafter for the youngest age groups.

\section{SOME EXPLANATORY FACTORS OF THE DIFFERENCES IN THE LEVEL OF SKILLS BY AGE GROUP}

This section aims at complementing the evidence provided in sections 3 and 4 with an additional analysis centred on explaining aggregate differences in skills between age groups located at the extremes of the age distribution. The unit of analysis is, therefore, the age group.

Table 5 and Figure 1 show the differences in both numeracy and literacy skills as a function of age. Both skills increase from the youngest age group to the 26-30 (in the case of literacy) and 31-35 (in the case of numeracy) age groups. Subsequently, the trend decreases, the level of skills reaching a minimum in the older age groups. In this process of skill loss after the respective prime ages, two factors operate: on the one hand, ageing, defined in section 3 as a biological and behavioural process; and, on the other, levels of schooling, which, due to the progressive quantitative extension of education, are generally higher for the younger age groups. Graph 4 shows this progressive extension, including the corresponding 95\% confidence interval. The maximum level of schooling is reached for those aged 30, with an average of 14 years of schooling, while for people aged 65 the average value drops to 11.9 years.

[Table 5 about here]

[Figure 4 about here]

In the following analysis, we selected the 31-35 year age group as being representative of the prime age groups with a high probability of having completed their degree and entered the labour market. We compared the skills of this age group with those of the 
older age group (60-65) and sought to identify the contribution in the difference found in the two main factors (as identified above) determining this skill loss.

The following formulation was used to disentangle the two factors. The equation that explains skills is given by:

$$
Y_{i}=X_{i}^{\prime} \beta+u_{i}
$$

This equation enabled us to compute the average skills of a certain $\mathrm{Y}$ age group $\mathrm{J}$ by calculating the corresponding average values of all individuals belonging to this group:

$$
\bar{Y}=\bar{X}^{\prime} \beta+\bar{u}
$$

In the same way, for age group $\mathrm{O}$, it was possible to calculate:

$$
\overline{\bar{Y}}=\overline{\bar{X}}^{\prime} \beta+\overline{\bar{u}}
$$

where the upper double line indicated the average values of all individuals belonging to age group $\mathrm{O}$.

The difference in the average skills of cohorts $\mathrm{J}$ and $\mathrm{O}$ could then be decomposed as follows:

$$
\underbrace{(\overline{\mathrm{Y}}-\overline{\overline{\mathrm{Y}}})}_{\begin{array}{c}
\text { Observed } \\
\text { difference }
\end{array}}=\underbrace{\left(\bar{X}^{\prime}-\overline{\bar{X}}^{\prime}\right) \beta}_{\begin{array}{c}
\text { Explained } \\
\text { difference }
\end{array}}+\underbrace{(\bar{u}-\overline{\bar{u}})}_{\begin{array}{c}
\text { Unexplained } \\
\text { difference }
\end{array}}
$$

Substituting the population parameters by the corresponding estimates, we were able to disaggregate the variation of skills for different age groups.

Table 6 shows the results of comparing the numeracy and literacy skills of the older age group (61-65 years old) with those of the prime age group (31-35 years old). In the case of numeracy skills, the observed difference between age groups was 50.27 points while the estimated difference was 48.81 points, which suggests that our model fits the actual change well (the unexplained difference representing barely $2.9 \%$ ). With our model, we could disentangle the contribution of, first, age and experience in the labour market (which amounts to 24.6 points or $48.99 \%$ of the total difference); second, schooling, including both formal initial education [9] and subsequent participation in non-formal learning and training programmes (which amounts to 17.6 points or $35.09 \%$ of the total difference); and, third, other factors related to the composition of the population, gender, etc. (amounting to 6.5 points or $13.02 \%$ of the total difference). The Table also shows the results of our analysis for literacy skills. The contribution of age and experience in determining differences between age groups for these skills $(45.74 \%$ of the total) is slightly lower than that observed for numeracy skills, whilst the contribution of schooling is higher $(44.78 \%$ of the total).

\section{[Table 6 about here]}

Our results point to the combined action of the two factors under consideration, with a contribution of age and experience that accounts for almost half the total difference. The ageing factor, driving skills downwards, threatens the growth potential of our economies, especially if we take into account the long-term trend of ageing in most developed societies. Moreover, it is a factor that is, to a large extent, beyond the control 
of public policies. However, the expansion of schooling partially offsets this decline in skills with ageing, with the participation of individuals in the educational system being a factor that can be modified by policy measures. Specifically, schooling -in the sense we give it - can be increased by means of educational policy, either through the straightforward quantitative expansion of formal education or by improvements in its quality. Moreover, an intensification of non-formal learning and training programmes could also be useful to partially offset the negative effect of ageing on skills. Additional interventions, aimed at reshaping learning so as to avoid the rapid skill loss we detected in the years immediately after leaving formal education, could also be envisaged. To sum up, several options are available for seeking to compensate the decay in skills associated with ageing.

\section{CONCLUSIONS}

This article aimed to analyse how adult skills changed across age groups, disentangling two factors of change: on the one hand, an ageing effect and, on the other, a cohort effect related to changes over time in the quality of schooling. Adult skills were examined in terms of cognitive skills as assessed in the OECD's PIAAC. This aim is of some relevance, especially if we take into account the relation between age and skills: an individual's numeracy and literacy skills increase up to the age of about 25-30 years and, after this, tend to decrease continuously. Our research question was centred on the factors associated with that trend.

We drew on data for 16 countries participating in the first edition of PIAAC (2012). We estimated a model in which numeracy and literacy skills were related to a set of variables, among which we included our two variables of interest. The first was a functional form of schooling which combined education level with age, indicating the efficiency of the educational system in transforming schooling into skills. The model allowed this efficiency to vary both between age groups and education levels. The second variable was a functional form of age which captured the direct ageing effect (caused by processes related simultaneously to biological and behavioural maturation). Additionally, the model included other variables aimed at capturing and controlling a range of different sources of skill acquisition, namely family background, participation in the labour market and participation in non-formal learning programs.

Taking our two variables of interest into consideration, the estimation of the model yielded the following main results. First, the direct ageing effect decreased monotonically for all the age groups considered. Second, we found very similar cohort effects in relation to the efficiency in the transformation of schooling into skills for numeracy and literacy skills. Third, the cohort effect varied substantially between upper secondary education and higher education. And fourth, the cohort effect for upper secondary education showed a steady level of efficiency over time, whilst, in the case of higher education, efficiency increased for all the age groups between 1945 and 1970, decreasing slightly thereafter for the youngest age groups.

The evidence provided by the article is complemented, in section 5 byan analysis in which we sought to explain aggregate differences in skills between the age groups 
located at the extremes of the age distribution (31-35 years vs. 60-65 years), the unit of analysis being the age group. These differences were split into two components with opposite effects: ageing, which tends to decrease skills, and levels of schooling, which, in recent decades, have shown a persistent quantitative extension of skills. Our results indicate that age accounts for almost half the total difference in skills between the two selected age groups, whilst changes in schooling, including quantitative and possible qualitative changes, account for $35.09 \%$ (in the case of numeracy) and $44.78 \%$ (literacy) of the difference.

All in all, the results provided by this article show that ageing, a factor of increasing significance in most developed societies, drives skills downwards, all else being constant, and also that quantitative expansions and qualitative improvements of schooling can be used by public policy as a means to partially compensate for this trend.

\section{REFERENCES}

Björklund, A. \& Salvanes, K.G. (2011). Education and family background: mechanism and policies, in E. A. Hanushek, S. Machin, \& L. Woessman (Eds.), Handbook of the economics of education. North-Holland, Amsterdam.

Borghans, L., Green, F., \& Meyhew, K. (2001). Skills measurement and economic analysis: An introduction. Oxford Economics Papers, 53, 375-384.

De Grip, A. \& Van Loo, J. (2002). The economics of skills obsolescence: A review. The economics of skills obsolescence: theoretical innovations and empirical applications, 21, 1-26.

Desjardins, R. \& Warnke, A. (2012). Ageing and skills: A review and analysis of skill gain and skill loss over the lifespan and over time. OECD Education Working Paper, 72. Paris: OECD Publishing. hppt://dx.doi.org/10.1781/5k9csvw87ckh-en

Flisi. S., Meroni, E.C, \& Vera-Toscano, E. (2015). Skills beyond education: An analysis of cognitive skill evolution and its implications for employment chances. JRC Science and Policy Reports, European Commission (Report EUR 27194), Luxembourg.

Green, D.A. \& Riddell, W.C. (2007). Literacy and the labour market: the generation of literacy and its impact on earnings for native born Canadians. Ottawa: Statistics Canada.

Green, D.A. \& Riddell, W.C. (2013). Ageing and literacy skills: evidence from Canada, Norway and the United States, Labour Economics, 22, 16-29.

Hanushek, E.A. (1979). Conceptual and empirical issues in the estimation of educational production functions, Journal of Human Resources, 14, 351-388.

Hanushek, E.A. (1997). Assessing the effects of school resources on student performance: An update, Educational Evaluation and Policy Analysis, 19, 141-164.

Hanushek, E.A. \& Woessman, L. (2008). The role of cognitive skills in economic development, Journal of Economic Literature, 46, 607-668.

Hertzog, C., Kramer, A.F., Wilson, R.S., \& Lindenberger, U. (2009). Enrichment effects on adult cognitive development, Psychological Science in the Public Interest, 9, $1-65$. 
Mazzona, F. (2014). The long-lasting effects of family background: a European crosscountry comparison, Economics of Education Review, 40, 25-42.

OECD (2012). Literacy, numeracy and problem-solving in rich-technology environments: framework for the OECD Survey of Adult Skills, OECD Publishing. http://dx.doi.org/10.1787/9789264128859-en.

Reder, S. (2009). The development of adult literacy and numeracy in adult life, in: S. Reder \& J. Bynner (Eds.), Tracking adult literacy and numeracy skills: findings from longitudinal research, Routledge: New York.

St. Clair, R. (2012): The limits of levels: Understanding the International Adult Literacy Surveys (IALS), International Review of Education, 58, 759-777.

Willms, S.L. \& Murray, T.S. (2007). Gaining and losing literacy skills over the lifecourse (Catalogue n. 89-552-XIE, n 16), Ottawa: Statistics Canada.

Wößmann, L. (2013). Specifying human capital, Journal of Economic Surveys, 17, 239270.

\section{NOTES}

[1] Nonetheless, social changes other than variations in schooling quality could persist in the comparison of successive cohorts. In other words, our strategy is suitable for capturing cohort differences in skills due to modifications in the quality of schooling but not for isolating total cohort effects from pure age effects. The latter requires spanned cross-sectional data to be implemented (Desjardins and Warnke, 2012).

[2] As noted by Desjardins and Warnke (2012), comparisons of the different waves of IALS (1994, 1996 and 1998), ILL (2003, 2007) and PIAAC (2012) can be conducted in two ways. On the one hand, the trajectory of, for example, those individuals born in 1965 and who were aged 33 in IALS-1998, 42 in ALL-2007 and 47 in PIAAC could be monitored. This comparison would reveal whether that cohort had gained or lost skills with ageing. On the other hand, individuals aged 33 in IALS-1994 could be compared with individuals aged 33 in ILL-2003 in order to determine whether there had been a positive or a negative cohort effect in terms of skills for this particular group.

[3] Homogeneous, complete data are available for Belgium, Czech Republic, Denmark, Estonia, Finland, Ireland, Italy, Japan, Korea, Netherlands, Norway, Poland, Slovak Republic, Spain, Sweden and the United Kingdom.

[4] Nonetheless, it is reasonable to assume that in the period of time considered in our study (individuals in the sample were born between 1946 and 1995) no significant cohort effects, other than the one controlled for in the model, have come into play.

[5] A description of the selected explanatory variables is provided in Table A.1.

[6] The choice of these categories is endorsed by the evidence provided in Table 3. Thus, the rate of return to schooling in terms of acquired skills differs notably between the intermediate and higher education levels.

[7] When applying a formal test of equality of coefficients on intermediate education, the null hypothesis is rejected with a p-value of $1.77 \%$. Moreover, the specific null hypothesis of equality between the coefficient of the first age group and the coefficient of the rest of the age groups is also rejected, with a zero p-value. Nonetheless, the pronounced fall in the coefficient associated with the first cohort should be interpreted with caution, as some sample effects might contaminate the result. Thus, the percentage of individuals belonging to both this cohort and this 
educational level varies greatly by country, a feature that is exclusive to this age group. As a consequence, the lower coefficient might be the result of an overrepresentation of those countries in which intermediate education shows a poorer efficiency in the transformation of schooling into skills.

[8] The null hypothesis of equality between the coefficient of the first age group and the coefficient of the last age group is also rejected, with a zero $\mathrm{p}$-value.

[9] Possible changes in the efficiency of the transformation of schooling into skills through successive cohorts, as described in sections 3 and 4 herein, are included in this factor. 
TABLE 1 Descriptive statistics

\begin{tabular}{lrrrr}
\hline Variable & Mean & Std. Dev. & Min & Max \\
\hline Numeracy & 542.0646 & 96.1126 & 49.6917 & 888.2642 \\
Literacy & 549.3120 & 88.3885 & 47.1337 & 831.2783 \\
Schooling & 12.7323 & 3.0259 & 3.0000 & 22.0000 \\
Age & 39.9555 & 14.4749 & 16.0000 & 65.0000 \\
Experience & 18.2143 & 13.1439 & 0.0000 & 55.0000 \\
Gender: male & 0.4783 & 0.4995 & 0.0000 & 1.0000 \\
Immigrant1 & 0.0796 & 0.2707 & 0.0000 & 1.0000 \\
Immigrant2 & 0.0173 & 0.1304 & 0.0000 & 1.0000 \\
Nativespeaker & 0.9233 & 0.2660 & 0.0000 & 1.0000 \\
Pared2 & 0.3815 & 0.4858 & 0.0000 & 1.0000 \\
Pared3 & 0.2232 & 0.4164 & 0.0000 & 1.0000 \\
Skilled occupation & 0.6122 & 0.4873 & 0.0000 & 1.0000 \\
Non formal learning & 0.3919 & 0.4882 & 0.0000 & 1.0000 \\
\hline
\end{tabular}


TABLE 2 Sample distribution by age and by education level

\begin{tabular}{ccc}
\hline Variable & & Percentage \\
\hline Education level & Basic & 26.83 \\
Intermediate & 43.38 \\
Age group & Higher education & 29.79 \\
& $16-20$ & 8.79 \\
$21-25$ & 8.29 \\
$26-30$ & 9.98 \\
$31-35$ & 10.73 \\
$36-40$ & 11.59 \\
$41-45$ & 11.12 \\
$46-50$ & 10.58 \\
$51-55$ & 10.08 \\
$56-60$ & 9.12 \\
$61-65$ & 9.72 \\
\hline
\end{tabular}


TABLE 3 Returns to schooling by education level

\begin{tabular}{|l|r|r|c|c|c|}
\hline Education level & \multicolumn{2}{|c|}{ Coefficient } & \multicolumn{2}{|c|}{$\begin{array}{c}\text { Average } \\
\text { years of } \\
\text { schooling }\end{array}$} & $\begin{array}{c}\text { Returns by additional years of } \\
\text { schooling }\end{array}$ \\
\cline { 2 - 3 } & Numeracy & Literacy & & Numeracy & Literacy \\
\hline Intermediate & 43.85813 & 37.48626 & 12.32281 & - & - \\
\hline Higher education & 79.90233 & 71.25528 & 16.13928 & 9.44438185 & 8.8482341 \\
\hline
\end{tabular}


TABLE 4 Determinants of numeracy and literacy by education level and age cohorts

\begin{tabular}{|c|c|c|}
\hline VARIABLES & Numeracy & Literacy \\
\hline \multicolumn{3}{|l|}{ Education: see graph 3} \\
\hline \multicolumn{3}{|l|}{ Age: see graph 2} \\
\hline Sex: male & $20.88(37.84)$ & $3.607(7.101)$ \\
\hline Immigrant1 & $-29.82(-18.08)$ & $-34.14(-22.09)$ \\
\hline Immigrant2 & $-11.68(-5.316)$ & $-13.16(-6.331)$ \\
\hline Nativespeaker & $31.44(17.92)$ & 29.34 (17.89) \\
\hline Pared2 & $16.08(23.16)$ & $15.41(24.03)$ \\
\hline Pared3 & $35.96(43.89)$ & $33.99(44.90)$ \\
\hline Experience & $1.437(10.67)$ & $1.102(8.860)$ \\
\hline Experiencie $^{2}$ & $-0.0197(-7.110)$ & $-0.0186(-7.264)$ \\
\hline Skilled occupation & $31.09(48.48)$ & $26.08(43.98)$ \\
\hline Non formal education & $11.95(20.15)$ & $11.83(21.62)$ \\
\hline Czech Republic & $-10.76(-6.918)$ & $-4.452(-3.043)$ \\
\hline Denmark & $-3.229(-2.105)$ & $-9.624(-6.820)$ \\
\hline Estonia & $33.78(19.31)$ & $42.78(25.80)$ \\
\hline Finland & $6.128(3.881)$ & $26.93(18.20)$ \\
\hline Ireland & $-32.93(-20.09)$ & $-4.316(-2.893)$ \\
\hline Italy & $-24.83(-13.62)$ & $-15.89(-9.576)$ \\
\hline Japan & $4.248(2.674)$ & $29.11(20.08)$ \\
\hline Korea & $-34.47(-22.36)$ & $-9.235(-6.517)$ \\
\hline Netherlands & $9.589(6.064)$ & 25.97 (17.59) \\
\hline Norway & $-5.049(-2.973)$ & $3.600(2.350)$ \\
\hline Poland & $-37.46(-23.89)$ & $-15.95(-10.91)$ \\
\hline Slovak Republic & $-0.915(-0.565)$ & $0.680(0.461)$ \\
\hline Spain & $-43.04(-25.93)$ & $-25.19(-16.00)$ \\
\hline Sweden & $7.444(4.270)$ & $16.45(10.38)$ \\
\hline United Kingdom & $-30.45(-19.95)$ & $-1.470(-1.043)$ \\
\hline Constant & $470.4(124.3)$ & 489.5 (136.9) \\
\hline Observations & 78,825 & 78,825 \\
\hline R-squared & 0.341 & 0.348 \\
\hline
\end{tabular}


TABLE 5 Numeracy and literacy skills by cohort

\begin{tabular}{|c|c|c|c|c|}
\hline Age & Cohort & Value & Lower limit & Upper limit \\
\hline \multicolumn{5}{|c|}{ Numeracy skills } \\
\hline $16-20$ & 1 & 539.8514 & 538.0194 & 541.6835 \\
\hline $21-25$ & 2 & 554.9839 & 553.2221 & 556.7457 \\
\hline $26-30$ & 3 & 559.1966 & 557.2661 & 561.1272 \\
\hline $31-35$ & 4 & 559.3848 & 557.4617 & 561.3078 \\
\hline $36-40$ & 5 & 556.5519 & 554.7032 & 558.4006 \\
\hline $41-45$ & 6 & 550.0798 & 548.191 & 551.9685 \\
\hline $46-50$ & 7 & 541.4388 & 539.5518 & 543.3258 \\
\hline $51-55$ & 8 & 527.7028 & 525.7611 & 529.6445 \\
\hline $56-60$ & 9 & 518.4784 & 516.5403 & 520.4165 \\
\hline $61-65$ & 10 & 509.1117 & 507.1988 & 511.0247 \\
\hline \multicolumn{5}{|c|}{ Literacy skills } \\
\hline $16-20$ & 1 & 557.5503 & 555.8869 & 559.2137 \\
\hline $21-25$ & 2 & 569.469 & 567.8694 & 571.0686 \\
\hline $26-30$ & 3 & 570.3308 & 568.5779 & 572.0836 \\
\hline $31-35$ & 4 & 567.1315 & 565.3854 & 568.8775 \\
\hline $36-40$ & 5 & 564.8601 & 563.1816 & 566.5387 \\
\hline $41-45$ & 6 & 554.5522 & 552.8373 & 556.2671 \\
\hline $46-50$ & 7 & 544.3747 & 542.6614 & 546.088 \\
\hline $51-55$ & 8 & 529.6294 & 527.8665 & 531.3924 \\
\hline $56-60$ & 9 & 518.9467 & 517.187 & 520.7064 \\
\hline $61-65$ & 10 & 510.0311 & 508.2942 & 511.768 \\
\hline
\end{tabular}


TABLE 6. Explanatory factor of the improvement in numeracy skills when passing from the old cohort (aged between 61 and 65 years) to prime age cohort (aged between 31 and 35 years)

\begin{tabular}{lcccc}
\hline & \multicolumn{2}{c}{ Value } & \multicolumn{2}{c}{ Percentage } \\
& Numeracy & Literacy & Numeracy & Literacy \\
\hline Contribution of age and experience & 24.63 & 26.12 & 48.99 & 45.74 \\
Contribution of schooling & 17.64 & 25.57 & 35.09 & 44.78 \\
Remaining factors & 6.54 & 4.67 & 13.02 & 8.17 \\
Explained variation & 48.81 & 56.35 & 97.10 & 98.69 \\
Non explained variation & 1.46 & 0.75 & 2.90 & 1.31 \\
Observed variation & 50.27 & 57.10 & 100.00 & 100.00 \\
\hline
\end{tabular}

FIGURE 1 Numeracy and literacy skills by age
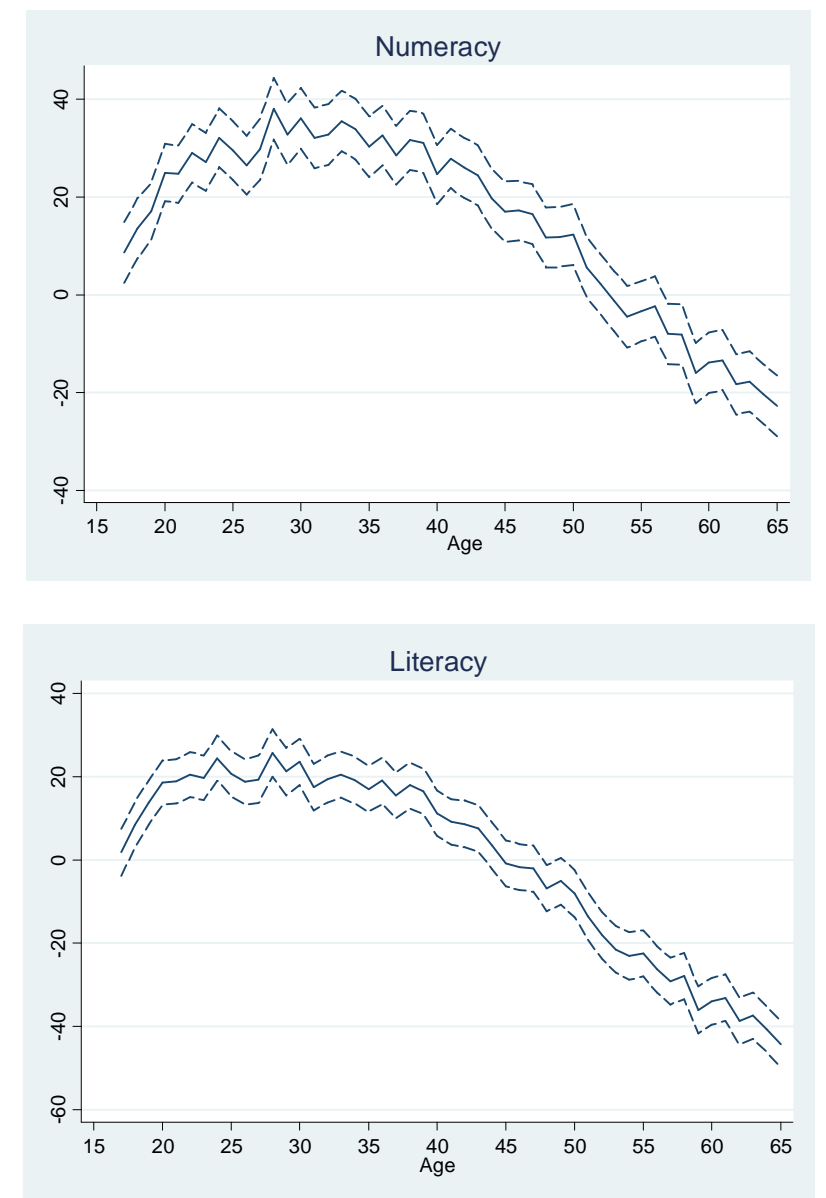
FIGURE 2 Effects of ageing on numeracy and literacy skills
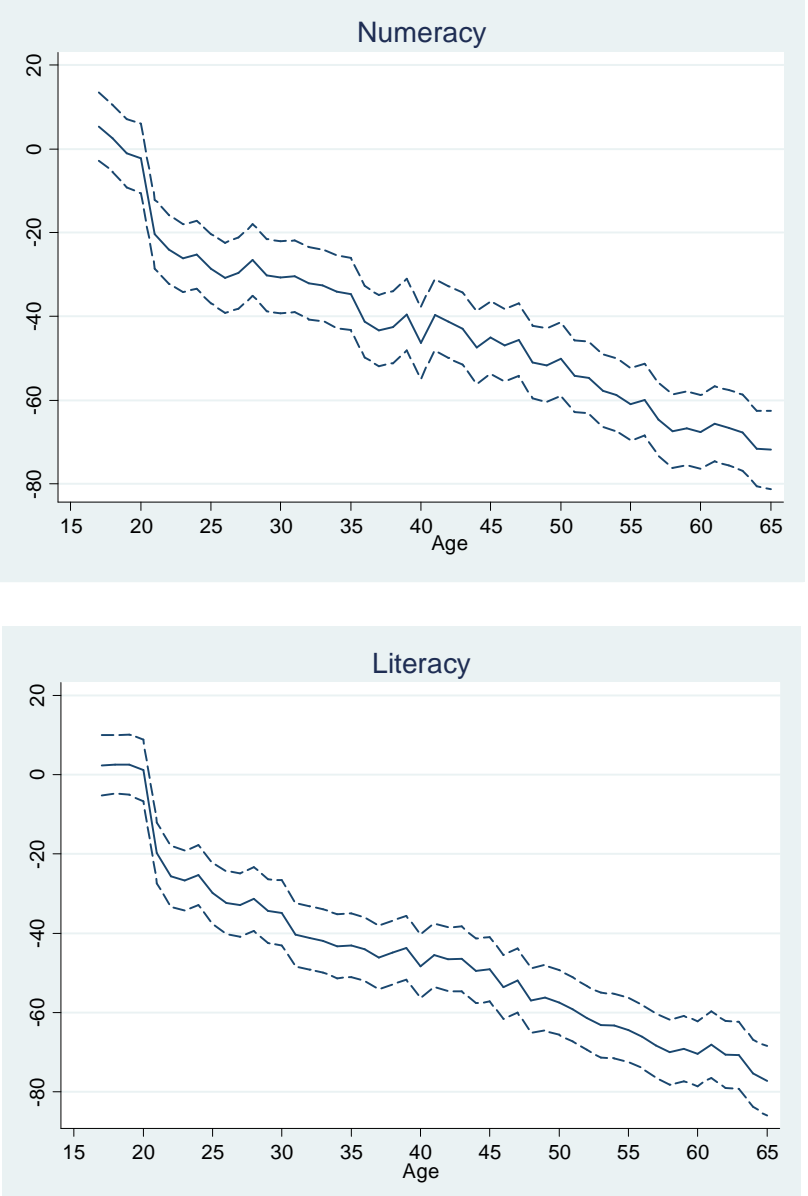
FIGURE 3 Efficiency on the transformation of schooling into skills

Numeracy

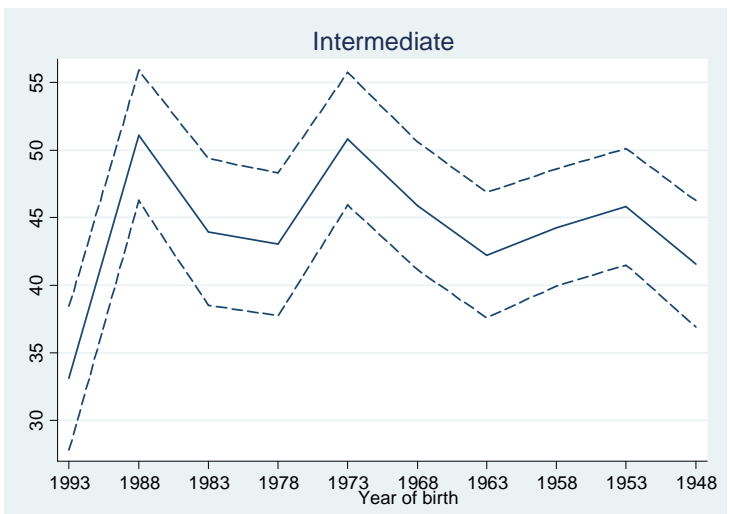

Higher

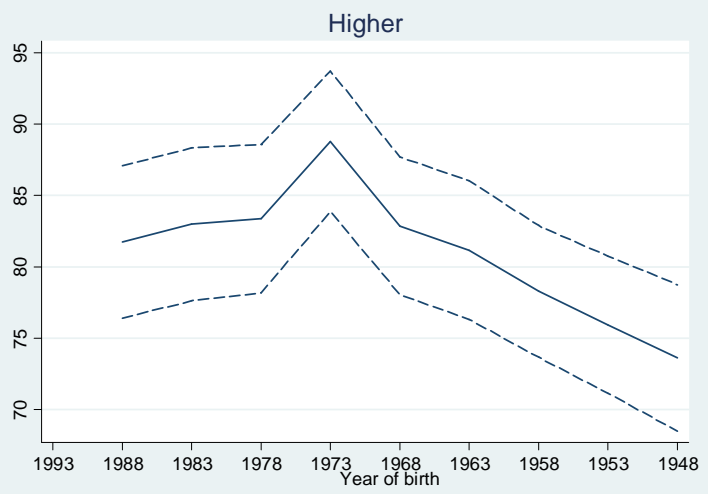

Literacy
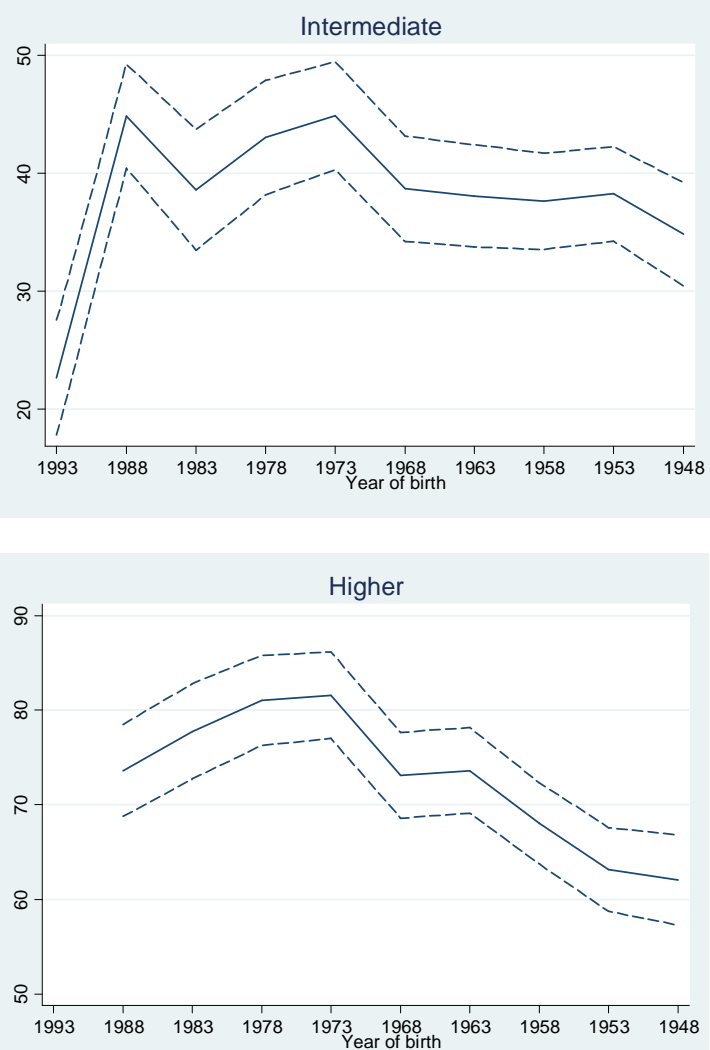

FIGURE 4 Average years of schooling by age

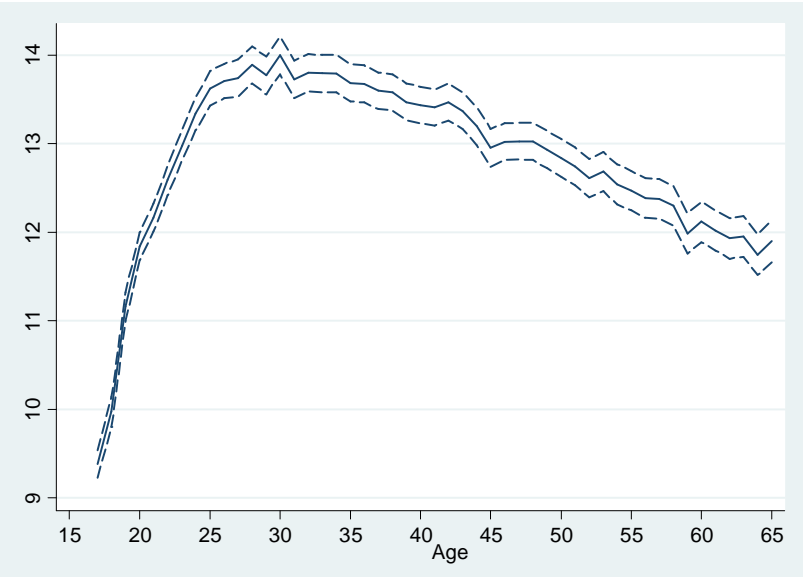


Annex

TABLE A1 Description of the variables

\begin{tabular}{|c|c|}
\hline VARIABLE & DEFINITION \\
\hline Pb1000m, Pb1000l & $\begin{array}{l}\text { Dependent variables: average numeracy (PVNUM1-10) and literacy (PVLIT1-10) skills normalized } \\
\text { to } 1000\end{array}$ \\
\hline$\beta_{1} \operatorname{lnt}_{\mathrm{i} 1 \ldots} \beta_{10} \operatorname{lnt}_{\mathrm{i} 10}$ & Dummies indicating that individuals born in the $1^{\text {st }} \ldots 10^{\text {th }}$ cohort hold upper secondary education \\
\hline$\alpha_{1} \operatorname{Sup}_{\mathrm{i} 1 \ldots} \alpha_{10} \operatorname{Sup}_{\mathrm{i} 10}$ & Dummies indicating that individuals born in the $1^{\text {st }} \ldots 10^{\text {th }}$ cohort hold higher education \\
\hline Age & Person resolved age: AGE_R \\
\hline Experience & Years of paid work during lifetime: C_Q09 \\
\hline Gender & Person resolved gender: GENDER_R \\
\hline Immigrant1 & First generation immigrants: IMGEN=1 \\
\hline Immigrant2 & Second generation immigrants: IMGEN=2 \\
\hline Nativespeaker & Respondent is native speaker: NATIVESPEAKER \\
\hline Pared2 & At least one parent has attained secondary or post-secondary, non-tertiary: PARED $=2$ \\
\hline Pared3 & At least one parent has attained tertiary: PARED $=3$ \\
\hline Skilled occupation & $\begin{array}{l}\text { Occupational classification of respondent's job ( } 4 \text { skill based categories), last or current (derived): } \\
\text { ISCOSKIL } 4=1\end{array}$ \\
\hline Non formal learning & Participated in non-formal learning in 12 months preceding survey (derived): NFE12=1 \\
\hline
\end{tabular}

TABLE A.2 Determinants of numeracy and literacy by education level and age cohorts

\begin{tabular}{lll}
\hline VARIABLES & \multicolumn{1}{c}{ Numeracy } & \multicolumn{1}{c}{ Literacy } \\
\hline Intermediate1 & $33.13^{* * *}$ & $22.67^{* * *}$ \\
& 12.21 & 9.141 \\
Intermediate2 & $51.09^{* * *}$ & $44.85^{* * *}$ \\
& 20.79 & 19.92 \\
Intermediate 3 & $43.95^{* * *}$ & $38.60^{* * *}$ \\
& 15.85 & 14.78 \\
Intermediate 4 & $43.04^{* * *}$ & $43.03^{* * *}$ \\
& 15.97 & 17.39 \\
Intermediate 5 & $50.85^{* * *}$ & $44.88^{* * *}$ \\
& 20.33 & 19.20 \\
Intermediate 6 & $45.89^{* * *}$ & $38.69^{* * *}$ \\
& 19.02 & 17.01 \\
Intermediate 7 & $42.24^{* * *}$ & $38.08^{* * *}$ \\
& 17.82 & 17.20 \\
Intermediate 8 & $44.28^{* * *}$ & $37.62^{* * *}$ \\
& 20.01 & 18.04 \\
Intermediate 9 & $45.81^{* * *}$ & $38.25^{* * *}$ \\
& &
\end{tabular}




\begin{tabular}{|c|c|c|}
\hline \multirow{3}{*}{ Intermediate 10} & 20.85 & 18.74 \\
\hline & $41.60 * * *$ & $34.85 * * *$ \\
\hline & 17.50 & 15.61 \\
\hline \multirow[t]{2}{*}{ Higher1 } & 1.218 & -4.199 \\
\hline & 0.147 & -0.477 \\
\hline \multirow[t]{2}{*}{ Higher2 } & $81.73 * * *$ & $73.63 * * *$ \\
\hline & 29.99 & 29.64 \\
\hline \multirow[t]{2}{*}{ Higher3 } & $82.97 * * *$ & $77.78 * * *$ \\
\hline & 30.40 & 30.24 \\
\hline \multirow[t]{2}{*}{ Higher4 } & $83.36 * * *$ & $81.05^{* * *}$ \\
\hline & 31.42 & 33.38 \\
\hline \multirow{2}{*}{ Higher5 } & $88.79 * * *$ & $81.57 * * *$ \\
\hline & 35.40 & 34.97 \\
\hline \multirow[t]{2}{*}{ Higher6 } & $82.87^{* * *}$ & $73.13^{* * *}$ \\
\hline & 33.70 & 31.60 \\
\hline \multirow[t]{2}{*}{ Higher7 } & $81.16^{* * *}$ & $73.63 * * *$ \\
\hline & 32.72 & 31.92 \\
\hline \multirow[t]{2}{*}{ Higher8 } & $78.27^{* * *}$ & $68.04 * * *$ \\
\hline & 33.30 & 31.02 \\
\hline \multirow[t]{2}{*}{ Higher9 } & $75.95 * * *$ & $63.17 * * *$ \\
\hline & 30.97 & 27.93 \\
\hline \multirow[t]{2}{*}{ Higher10 } & $73.62 * * *$ & $62.04 * * *$ \\
\hline & 28.12 & 25.48 \\
\hline \multicolumn{3}{|l|}{ Age } \\
\hline \multirow[t]{2}{*}{17} & 5.321 & 2.352 \\
\hline & 1.277 & 0.605 \\
\hline \multirow[t]{2}{*}{18} & 2.493 & 2.595 \\
\hline & 0.613 & 0.686 \\
\hline \multirow[t]{2}{*}{19} & -1.092 & 2.534 \\
\hline & -0.263 & 0.656 \\
\hline \multirow[t]{2}{*}{20} & -2.263 & 1.073 \\
\hline & -0.532 & 0.272 \\
\hline \multirow[t]{2}{*}{21} & $-20.34 * * *$ & $-19.74 * * *$ \\
\hline & -4.838 & -5.043 \\
\hline \multirow[t]{2}{*}{22} & $-24.02 * * *$ & $-25.64 * * *$ \\
\hline & -5.726 & -6.520 \\
\hline \multirow[t]{2}{*}{23} & $-26.09 * * *$ & $-26.67 * * *$ \\
\hline & -6.327 & -6.929 \\
\hline \multirow[t]{2}{*}{24} & $-25.24 * * *$ & $-25.39 * * *$ \\
\hline & -6.101 & -6.588 \\
\hline \multirow[t]{2}{*}{25} & $-28.58 * * *$ & $-29.91 * * *$ \\
\hline & -6.785 & -7.642 \\
\hline \multirow[t]{2}{*}{26} & $-30.76 * * *$ & $-32.23 * * *$ \\
\hline & -7.182 & -7.977 \\
\hline \multirow[t]{2}{*}{27} & $-29.60 * * *$ & $-32.84 * * *$ \\
\hline & -6.809 & -8.018 \\
\hline
\end{tabular}




\begin{tabular}{|c|c|}
\hline$-26.52 * * *$ & $-31.32 * * *$ \\
\hline-6.088 & -7.603 \\
\hline$-30.17 * * *$ & $-34.39 * * *$ \\
\hline-6.886 & -8.392 \\
\hline$-30.66 * * *$ & $-34.80 * * *$ \\
\hline-6.954 & -8.336 \\
\hline$-30.40 * * *$ & $-40.38 * * *$ \\
\hline-6.967 & -9.927 \\
\hline$-32.06 * * *$ & $-41.13 * * *$ \\
\hline-7.290 & -10.07 \\
\hline$-32.56 * * *$ & $-41.86 * * *$ \\
\hline-7.457 & -10.29 \\
\hline$-34.11 * * *$ & $-43.22 * * *$ \\
\hline-7.734 & -10.52 \\
\hline$-34.62 * * *$ & $-43.03 * * *$ \\
\hline-7.839 & -10.48 \\
\hline$-41.23 * * *$ & $-44.04 * * *$ \\
\hline-9.484 & -10.79 \\
\hline$-43.40 * * *$ & $-46.03 * * *$ \\
\hline-10.02 & -11.31 \\
\hline$-42.55 * * *$ & $-44.82 * * *$ \\
\hline-9.690 & -10.89 \\
\hline$-39.57 * * *$ & $-43.64 * * *$ \\
\hline-9.053 & -10.66 \\
\hline$-46.32 * * *$ & $-48.25 * * *$ \\
\hline-10.59 & -11.78 \\
\hline$-39.66 * * *$ & $-45.48 * * *$ \\
\hline-9.140 & -11.11 \\
\hline$-41.34 * * *$ & $-46.49 * * *$ \\
\hline-9.454 & -11.31 \\
\hline$-42.94 * * *$ & $-46.44 * * *$ \\
\hline-9.760 & -11.20 \\
\hline$-47.41 * * *$ & $-49.45 * * *$ \\
\hline-10.71 & -11.95 \\
\hline$-45.02 * * *$ & $-49.04 * * *$ \\
\hline-10.20 & -11.78 \\
\hline$-46.86 * * *$ & $-53.49 * * *$ \\
\hline-10.64 & -12.96 \\
\hline$-45.58 * * *$ & $-51.87 * * *$ \\
\hline-10.29 & -12.53 \\
\hline$-50.94 * * *$ & $-56.94 * * *$ \\
\hline-11.50 & -13.76 \\
\hline$-51.67 * * *$ & $-56.19 * * *$ \\
\hline-11.53 & -13.37 \\
\hline$-50.11 * * *$ & $-57.40 * * *$ \\
\hline-11.22 & -13.76 \\
\hline
\end{tabular}


51

52

53

54

55

56

57

58

59

60

61

62

63

64

65

Sex: male

Immigrant1

Immigrant2

Nativespeaker

Pared2

Pared3

Experience

Experiencie $^{2}$

\begin{tabular}{|c|c|}
\hline$-54.25 * * *$ & $-59.14 * * *$ \\
\hline-12.41 & -14.42 \\
\hline$-54.65 * * *$ & $-61.35 * * *$ \\
\hline-12.48 & -14.94 \\
\hline$-57.69 * * *$ & $-63.14 * * *$ \\
\hline-13.02 & -15.17 \\
\hline$-58.71 * * *$ & $-63.31 * * *$ \\
\hline-13.15 & -15.20 \\
\hline$-60.95 * * *$ & $-64.32 * * *$ \\
\hline-13.88 & -15.58 \\
\hline$-59.87 * * *$ & $-66.00 * * *$ \\
\hline-13.67 & -16.15 \\
\hline$-64.60 * * *$ & $-68.30 * * *$ \\
\hline-14.60 & -16.51 \\
\hline$-67.36 * * *$ & $-69.98 * * *$ \\
\hline-15.00 & -16.80 \\
\hline$-66.70 * * *$ & $-69.06 * * *$ \\
\hline-14.91 & -16.49 \\
\hline$-67.56 * * *$ & $-70.31 * * *$ \\
\hline-15.12 & -16.82 \\
\hline$-65.67 * * *$ & $-67.97 * * *$ \\
\hline-14.33 & -15.88 \\
\hline$-66.59 * * *$ & $-70.54 * * *$ \\
\hline-14.51 & -16.35 \\
\hline$-67.73 * * *$ & $-70.73 * * *$ \\
\hline-14.63 & -16.33 \\
\hline$-71.54 * * *$ & $-75.27 * * *$ \\
\hline-15.58 & -17.50 \\
\hline$-71.86 * * *$ & $-77.17 * * *$ \\
\hline-15.01 & -17.30 \\
\hline $20.88 * * *$ & $3.607 * * *$ \\
\hline 37.84 & 7.101 \\
\hline$-29.82 * * *$ & $-34.14 * * *$ \\
\hline-18.08 & -22.09 \\
\hline$-11.68 * * *$ & $-13.16 * * *$ \\
\hline-5.316 & -6.331 \\
\hline $31.44 * * *$ & $29.34 * * *$ \\
\hline 17.92 & 17.89 \\
\hline $16.08 * * *$ & $15.41 * * *$ \\
\hline 23.16 & 24.03 \\
\hline $35.96 * * *$ & $33.99 * * *$ \\
\hline 43.89 & 44.90 \\
\hline $1.437 * * *$ & $1.102^{* * *}$ \\
\hline 10.67 & 8.860 \\
\hline$-0.0197 * * *$ & $-0.0186 * * *$ \\
\hline-7.110 & -7.264 \\
\hline
\end{tabular}




\begin{tabular}{|c|c|c|}
\hline \multirow[t]{2}{*}{ Skilled occupation } & $31.09 * * *$ & $26.08 * * *$ \\
\hline & 48.48 & 43.98 \\
\hline \multirow{2}{*}{ Non-formal learning } & $11.95^{* * *}$ & $11.83^{* * *}$ \\
\hline & 20.15 & 21.62 \\
\hline \multirow[t]{2}{*}{ Czech Republic } & $-10.76 * * *$ & $-4.452 * * *$ \\
\hline & -6.918 & -3.043 \\
\hline \multirow[t]{2}{*}{ Denmark } & $-3.229 * *$ & $-9.624 * * *$ \\
\hline & -2.105 & -6.820 \\
\hline \multirow[t]{2}{*}{ Estonia } & $33.78 * * *$ & $42.78 * * *$ \\
\hline & 19.31 & 25.80 \\
\hline \multirow[t]{2}{*}{ Finland } & $6.128 * * *$ & $26.93^{* * *}$ \\
\hline & 3.881 & 18.20 \\
\hline \multirow[t]{2}{*}{ Ireland } & $-32.93 * * *$ & $-4.316 * * *$ \\
\hline & -20.09 & -2.893 \\
\hline \multirow[t]{2}{*}{ Italy } & $-24.83 * * *$ & $-15.89 * * *$ \\
\hline & -13.62 & -9.576 \\
\hline \multirow[t]{2}{*}{ Japan } & $4.248^{* * *}$ & $29.11 * * *$ \\
\hline & 2.674 & 20.08 \\
\hline \multirow[t]{2}{*}{ Korea } & $-34.47 * * *$ & $-9.235 * * *$ \\
\hline & -22.36 & -6.517 \\
\hline \multirow[t]{2}{*}{ Netherlands } & $9.589 * * *$ & $25.97 * * *$ \\
\hline & 6.064 & 17.59 \\
\hline \multirow[t]{2}{*}{ Norway } & $-5.049 * * *$ & $3.600 * *$ \\
\hline & -2.973 & 2.350 \\
\hline \multirow{2}{*}{ Poland } & $-37.46 * * *$ & $-15.95^{* * *}$ \\
\hline & -23.89 & -10.91 \\
\hline \multirow[t]{2}{*}{ Slovak Republic } & -0.915 & 0.680 \\
\hline & -0.565 & 0.461 \\
\hline \multirow[t]{2}{*}{ Spain } & $-43.04 * * *$ & $-25.19 * * *$ \\
\hline & -25.93 & -16.00 \\
\hline \multirow[t]{2}{*}{ Sweden } & $7.444 * * *$ & $16.45^{* * *}$ \\
\hline & 4.270 & 10.38 \\
\hline \multirow[t]{2}{*}{ United Kingdom } & $-30.45 * * *$ & -1.470 \\
\hline & -19.95 & -1.043 \\
\hline \multirow[t]{2}{*}{ Constant } & $470.4^{* * *}$ & $489.5^{* * *}$ \\
\hline & 124.3 & 136.9 \\
\hline \multirow[t]{2}{*}{ Observations } & 78,825 & 78,825 \\
\hline & 0.341 & 0.348 \\
\hline
\end{tabular}

